\title{
Importance of using micronucleus test for hospital personnel exposed to cytostatics - Croatian study
}

\author{
Hrvoje Lalić \\ Medical School University Rijeka, Health Centre Rijeka, Croatia \\ Correspondence: Hrvoje Lalić. Address: Medical School University Rijeka, Health Centre Rijeka, Braće Branchetta 20, \\ 51000 Rijeka, Croatia. E-mail: hlalic@inet.hr
}

Received: September 12, 2012 Accepted: November 4, 2012

Online Published: November 18, 2012

DOI: $10.5430 /$ jha.v2n1p40

URL: http://dx.doi.org/10.5430/jha.v2n1p40

\section{Abstract}

Health personnel and administration is exposed to health risks. The paper's objective is to show that despite protection measures the exposed persons' health is damaged. The government and management show intentions to enhance protection programs but they lack the means because of recession. Twenty-seven employees of Clinical Centre Rijeka working with cytostatics have been analyzed by micronucleus test. In 11 nurses at the Pediatric oncology, 10 nurses at Internal hematology and 6 at Oncology there have been no significant differences in micronucleus test $(\mathrm{MN}), p=0.2106$, $p>0.05$, mean $10 \mathrm{MN}$, range 2-29. In one nurse from Pediatric oncology, four from internal hematology and two from Oncology differences from referential values in the number of MN/1000 binuclear cells were found and they were not allowed to work for six months. Occupational medicine has done its part for the hospital. Meanwhile the problem of payment according to the Rules guaranteeing special standard remains as MN test although compulsory is not a part of routine examination.

\section{Key words}

Occupational medicine, Micronucleus test, Health personnel

\section{Introduction}

In clinical and hospital centers medical and administration personnel is exposed to various damaging factors. According to the level of danger assessed by occupational medicine and work protection many employees perform their jobs under specific working conditions.

Among major potential dangers one can include infectious diseases, exposure to cytostatics, ionizing radiation, work in shifts, responsibility due to increased psychic burden where optimum concentration is required, etc.

Infectious diseases have been treated at the Infection Clinic and with routine measures of protection and isolation make no particular problem.

Regarding ionizing radiation Croatia follows the Vienna IAEA directives. The chromosome aberrations are not analyzed and more to diminish radiation to the least possible level. However, such a solution may be questioned since the zone of 
ionizing radiation always remains the zone of potential danger. Some years ago in the Republic of Croatia there were instances of increased aberration in exposed personnel ${ }^{[1]}$.

Not only Croatia but other countries as well had similar problems in hospitals using sources of radiation ${ }^{[2]}$. Besides chromosome aberrations other methods were used for biomonitoring like SCE test, micronuclei test ${ }^{[3]}$. Also in other professions, first of all anesthetists, genotoxicity appeared ${ }^{[4]}$.

Different types of carcinomas arise because of multiple changes in the genome of normal epithelial cells. The number of natural, spontaneous DNA lesions due to thermodynamic processes and the action of free radicals is usually about 70 million per cell per year, nevertheless, formation of the cancer is considered to be a billion-iterative system function, since after a total malignant transformation the cell has to divide some billions of times before a cancer forms. The malfunction of mismatch repair genes, which produces nuclear and mitochondrial genome instability, as well as the exposure to ionizing radiation and chemotherapeutic drugs, which activate a range of gene products, including the DNA repair pathways and cell-cycle check-points, might, however, play an important role in the origin of some hereditary and sporadic human cancers.

Regarding cytostatics Croatian Institute for health and Occupational safety issued Regulations on dealing with cytostatics in 2007 but such regulation existed as long ago as 1984, People's Gazette 3/1984, item 19.

Everyone in Croatia employed under specific working conditions is to be checked by occupational medicine. All occupational medicines in Croatia have been networked into an integral system through Croatian Institute for Health Safety to attain optimum health protection as well as monitoring lingering illnesses and work injuries at the national level. Therefore the Croatian Institute for Protection and Operational Safety with the headquarters in Zagreb insisted on greater care for the staff working with cytostatics. So also we as the field occupational medicine, whose task is health care for hospital employees, checked by micronucleus test (MN) a group of nurses working with cytostatics at IMI, the Institute for Occupational Medicine and Medical Research with its Mutagenesis Unit. MN has been used around the world as the most sensitive test for chromosome damage which has also been confirmed by the findings for the nurses obtained in that way ${ }^{[5]}$. Micronuclei are independent chromatic structures completely separated from nucleus. They develop by condensation of acentric chromosome fragments not built into sister cells ${ }^{[6]}$. MN assay may be a tool to biomonitor human exposure to aneuploidogens and clastogens ${ }^{[7]}$. So $\mathrm{MN}$ is also the indicator of structural and numerical chromosomal aberrations ${ }^{[8]}$. Our Institute for Occupational Medicine and Medical Research (IMI) has been recognized in scientific world, heading many projects, carrying out genetic analyses and detecting potential damages caused by professional exposure ${ }^{[9]}$.

The purpose of this paper is not to advocate MN test and genotoxic methods but to point out the need for monitoring hospital staff also by the tests such as MN test. That refers first of all to nurses that work on preparation and application of cytostatics who work in shifts and endanger their health helping the sick with malignant diseases. Furthermore, the intention of the paper is to point out the urgent need of settling such examinations into routine which demands health organization at the highest level from the Ministry of Health, Croatian Institute for Health Insurance and state hospital managements. The MN tests have become obligatory by the Regulations but so far IMI has not been reimbursed by Croatian Institute for Health Insurance for the analyzes carried out, based on the number of tested occupational medicine nurses. There is a question whether it is possible to continue MN tests as IMI cannot carry out such analyzes free of charge since they require relatively expensive chemicals such as Cytochalasin B, growth stimulation phytohaemagglutinin etc., not to mention expert knowledge of the Institute employees and the time spent in producing preparations and test interpretation.

\section{Examinees and methods}

\subsection{Examinees}

Published by Sciedu Press 
Twenty-seven employees of Clinical Hospital Center Rijeka have been examined at occupational medicine of Primorje Gorski kotar County's Health Center, which is educational unit of Medical School in Rijeka. Hospital Center Rijeka has about 3,000 medical and non-medical employees. Only the nurses performing the particular duties have been examined. The nurses that come in contact with cytostatics only sporadically have not been examined. Besides the routine examination of physical status, routine laboratory findings sedimentation, complete blood count, blood sugar, liver enzymes, urea and creatine, the blood was taken for the analysis in Zagreb at IMI for MN test. The nurses were from three different departments.

Table 1. Nurses at the Department of Pediatric Oncology

\begin{tabular}{llllll}
\hline Age & Yrs. exp. & No cigarette & $\mathbf{1 0}$ cigarette & $\mathbf{1 0 - 2 0}$ cigarette & MN \\
\hline 35 & 7 & 1 & 0 & 0 & 2 \\
46 & 7 & 1 & 0 & 0 & 10 \\
25 & 1 & 0 & 1 & 0 & 2 \\
41 & 19 & 0 & 1 & 0 & 29 \\
36 & 5 & 1 & 0 & 0 & 8 \\
51 & 10 & 0 & 1 & 0 & 12 \\
24 & 1 & 0 & 1 & 0 & 5 \\
53 & 29 & 1 & 0 & 0 & 6 \\
22 & 2 & 1 & 0 & 0 & 8 \\
27 & 1 & 1 & 0 & 0 & 3 \\
29 & 2 & 0 & 1 & 0 & 3 \\
\hline
\end{tabular}

Yrs. exp., years of exposure; No cigarette, without smoking cigarettes; 10 cigarette, average daily number of smoked cigarettes; 10-20 cigarette, average daily number of smoked cigarettes; MN, micronuclei.

The first group was made up of 11 nurses from Pediatric oncology department, mean aged 35.36 years, St.Dev. 11.0 range 23-53 years. Their average working experience with cytostatics was 7.63 years, St.Dev. 8.91, range 1-29 years (Table 1).

Table 2. Nurses at the Department of Internal medicine, Hematology

\begin{tabular}{llllll}
\hline Age & Yrs. exp. & No cigarette & $\mathbf{1 0}$ cigarette & $\mathbf{1 0 - 2 0}$ cigarette & MN \\
\hline 48 & 27 & 1 & 0 & 0 & 10 \\
35 & 15 & 0 & 0 & 1 & 4 \\
37 & 10 & 1 & 0 & 0 & 11 \\
44 & 21 & 1 & 0 & 0 & 16 \\
36 & 10 & 1 & 0 & 0 & 3 \\
57 & 16 & 0 & 0 & 1 & 13 \\
60 & 20 & 0 & 0 & 1 & 4 \\
62 & 16 & 0 & 0 & 1 & 18 \\
42 & 11 & 1 & 0 & 0 & 5 \\
49 & 27 & 1 & 0 & 0 & 5 \\
\hline
\end{tabular}

Yrs. exp., years of exposure; No cigarette, without smoking cigarettes; 10 cigarette, average daily number of smoked cigarettes; 10-20 cigarette, average daily number of smoked cigarettes; MN, micronuclei.

The second group consisted of 10 nurses from Internal Clinic, Hematology. Their mean age was 47.00 years, St.Dev. 16.36, range 10-27 (Table 2).

The third group numbered 6 nurses from Oncology Clinic, mean aged 45.16, St.Dev. 5.56, range 6-21. The number of micronuclei averaged 13.33, St.Dev. 6.74, range 7-24 (Table 3). 
Table 3. Nurses at the Department of Oncology

\begin{tabular}{llllll}
\hline Age & Yrs. exp. & No cigarette & 10 cigarette & 10-20 cigarette & MN \\
\hline 43 & 6 & 1 & 0 & 0 & 19 \\
46 & 20 & 1 & 0 & 0 & 7 \\
45 & 17 & 1 & 0 & 0 & 24 \\
47 & 20 & 1 & 0 & 0 & 12 \\
44 & 17 & 0 & 1 & 0 & 10 \\
46 & 21 & 1 & 0 & 0 & 8 \\
\hline
\end{tabular}

Yrs. exp., years of exposure; No cigarette, without smoking cigarettes; 10 cigarette, average daily number of smoked cigarettes; 10-20 cigarette, average daily number of smoked cigarettes; MN, micronuclei.

Figure 1. Differences between 3 groups of examinees according to the appearance of micronuclei (MN).

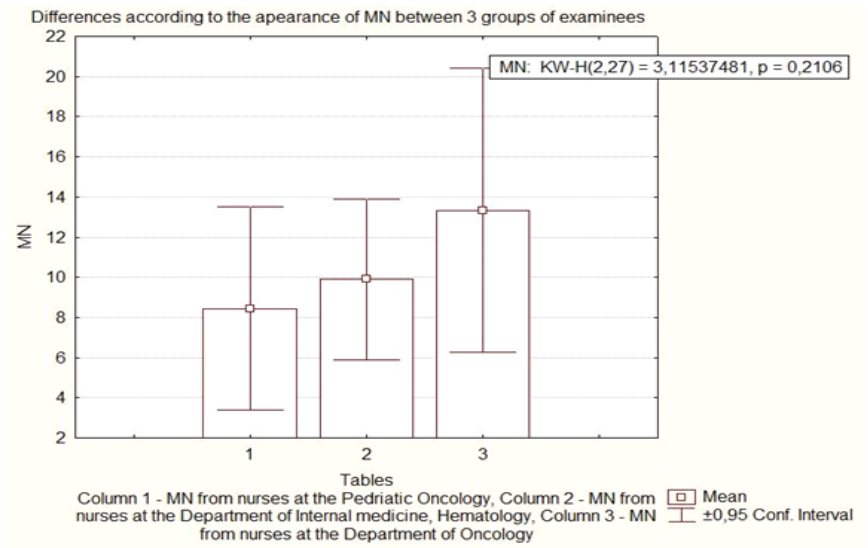

\subsection{Methods}

StatSoft, Statistics 6 program was used for data processing and creating figures.

Figure 2. Correlation between age and appearance of micronuclei in 3 groups of examinees

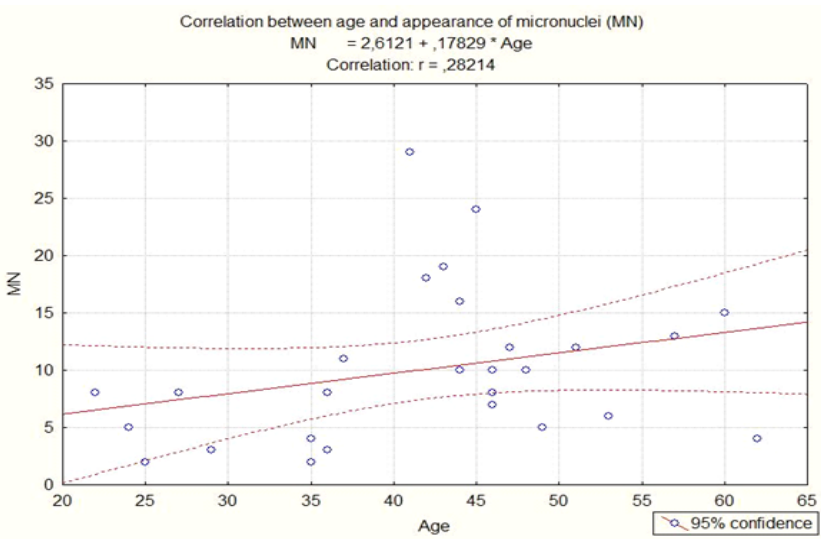

For MN assay standard protocol for cultivating cell cultures in vitro during 72 hours on 37 degrees was used. Cell cultures were received from peripheral blood lymphocytes. Growth medium was RPMI (Gibco) with 20\% fetal calf serum (Gibco), 
$1 \%$ phytohaemagglutinina (Apogent), and antibiotics penicillin $100 \mathrm{IU} \mathrm{mL}^{-1}$ (Pliva). Cytochalasin B, $6 \mu \mathrm{g} \mathrm{mL}^{-1}$ (Sigma) for cytokinesis-block was used. Centrifugation was done repeatedly a few times at $800 \mathrm{rpm}$. Glasses were stained by Giemsa (Sigma).

Figure 3. Correlation between years of exposure (Yrs. exp.) and appearance of micronuclei in 3 groups of examinees.

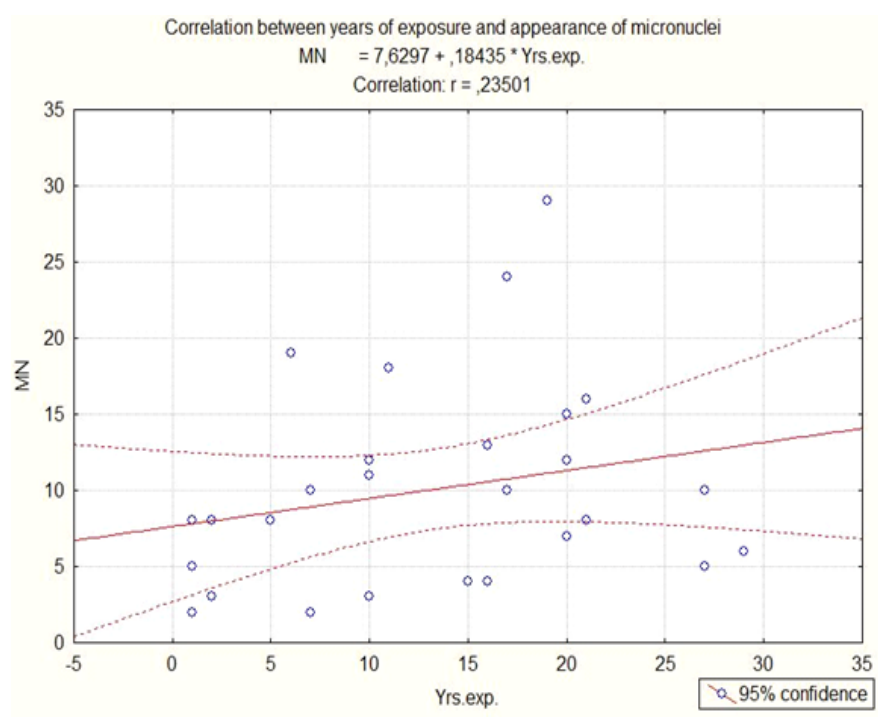

\section{Results}

The results of the nurses from Pediatric Oncology showed the mean number of micronuclei 8.45, St.Dev. 7.54, range 2-29. In the second group of nurses from Internal Clinic the nuclei mean number was 9.90, St.Dev. 5.58, range 3-18. With Oncology nurses the number of micronuclei averaged 13.33, St.Dev. 6.74, range 7-24 (Figure 1). Linear regression analysis showed positive correlation between age and number of nuclei (Figure 2).

The years of exposure and the number of nuclei showed positive correlation (Figure 3).

\section{Discussion}

As it was mentioned in the introduction infectious diseases because of the experienced medical staff, good isolation measures, prevention and adequate procedure are nowadays not a problem in our country. Of course, there are sporadically occurrences of infection and contagion with medical personnel. So there was a case of rare middle ear tuberculosis caused by mycobacterium tuberculosis at Pulmology Department of Clinical Hospital Center Rijeka in 2010 which was recognized as a professional disease ${ }^{[10]}$.

For the staff working in the radiation zone chromosomal aberrations are no longer analyzed. All dosimeter findings show very low professional exposure in microsieverts. In case of an accident or when the dose received is above the allowed limit for 1 year (20,000 microsieverts) the employee's chromosomal aberrations would be analyzed. Chromosome aberration analyzes are also performed at Biology Institutes of Medical Schools in the Republic of Croatia. There are four of them: in Rijeka, Zagreb, Osijek and Split so the situation is better than with the micronucleus test analysis because the only laboratory for mutagenesis with the official license is the IMI Cytogenetic laboratory.

At the moment one of major problems in our hospital center seems to be the work with cytostatics. 
As soon as the results of the analysis by micronucleus test were obtained we, as the occupational medicine in charge of examining people working under specific working conditions, networked through Croatian Institute for Health Insurance, informed the Clinical Hospital Center Occupational Safety Department as well as the tested nurses and the headquarters of Croatian Institute for Protection and Operational Safety in Zagreb.

The results were not received well by the exposed nurses, i.e. they expressed frustration and extreme worry, aware of the situation. Most of them are registered nurses with a 3 - year course at the Medical School or at least 4 - year secondary school for nurses. Besides, they all completed one - year obligatory traineeship before taking the state exam to be allowed to work independently. It is known that increased micronuclei in peripheral blood lymphocytes may mean an early cancer risk biomarker ${ }^{[11]}$.

Occupational medicine was bound to pronounce a 6-month temporary work ban for 7 nurses with the number of micronuclei increased to referential values.

But there are nurses with the findings or near the allowed limit. Also there was one case of increased micronuclei in a non-medical employee, a department cleaning woman. She washes up, cleans the floors and working tables where cytostatics are prepared and so she is exposed.

As there were no MN tests before, the initial state is not known. Namely, some persons might have genetic variability regardless of the exposure. Considering the examined nurses' smoking there was no positive correlation between number of cigarettes and increased micronuclei.

As hinted in the introduction, the intention of the paper is not to describe the MN test and it's proved advantages but something completely different.

The purpose of this paper is to influence those who manage human resources, the government, Ministry of Health and Croatian Institute for Health Insurance to enable better functioning of health system regarding more sophisticated and more expensive examination, not included in the domain of the routine checks.

In the chapter "Examinees and Methods" it was already mentioned that Occupational medicine examinations include physical findings and routine blood test with enzymes. In our town Rijeka and in the whole of Republic of Croatia no one but IMI is licensed to work with micronucleus test so our nurses' blood had to be sent to IMI in Zagreb. The Institute did us a favor by sending their employee who took blood from 27 employees and carried the samples to Zagreb for analysis. There is another problem: with 7 nurses the MN findings differ from referential values. It means that we as Occupational medicine after 6 months have to send those 7 nurses to have their blood taken again at IMI to assess whether they may work with cytostatics. It should be implemented. If it is not their future working ability is in question. While the nurses are forbidden to work they can perform other nurses' duties, but they must not work with cytostatics. In 2008 Occupational medicine in the Republic of Croatia took over sick leave from family practice, but since 2010 it has again been the responsibility of family doctors ${ }^{[12]}$. In the two - year period occupational medicine diminished sick leave at the national level for more than $50 \%$ compared to family practice. So occupational medicine has justified its existence and activity but the health system has returned the assessment to family doctors. Namely, the patients had to visit us at occupational medicine, then again their family physicians which caused a problem, particularly for the patient that lives far from the surgery.

In the Republic of Croatia the Institute for Health Protection and Operational Safety has successfully taken our medicine towards the EU on the principles of modern occupational health services ${ }^{[13]}$. But between plans and realization in practice there are always problems. One of them is paying for examinations which are not standard routine tests for persons doing 
the jobs under specific working conditions. By the Regulations MN tests are obligatory when one works with cytostatics so the health system should pay for them.

The occurrence of micronuclei does not yet mean illness but the warning that it might appear and in on such a case it would mean a malignant illness. As occurrence of $\mathrm{MN}$ is not an illness nurses cannot be diagnosed a professional disease, i.e. they cannot be given sick leave in the amount of $100 \%$ of regular salary. If a nurse is not given another workplace during the ban she has to take sick leave which is not paid $100 \%$, but is considered "standard" sick leave amounting to $70 \%$ of the usual pay for her qualification. Many of the nurses are self - supporting mothers and the cut in salary at these recession times is a problem. It is known that they work even when not quite fit, despite various problems, "as long as they can stay on their feet" to gain full payment ${ }^{[14]}$. It is extremely important for hospitals to have managements sensitive to the employed meeting their needs as much as possible, for satisfied employees would attain considerably better results which is to the advantage of the managers as well ${ }^{[15]}$.

By knowing and respecting workers' social status, life and health conditions sick leave can be prevented ${ }^{[16]}$.

In fact nurses enter ethical conflict since regardless of their status towards hospital management and strict rules, their own feelings and health conditions they always have to concentrate on the patient and carry out their job professionally ${ }^{[17]}$. Nurses are under stress and they are inclined to take sick leave so the number of the lost working days surely presents a problem for nursing personnel management ${ }^{[18]}$. Therefore it is necessary to promote nurses' health and benefit in order to reduce stress at work but also at home ${ }^{[19]}$. It has been observed that stress causes mainly short term sick leaves which also have to be prevented ${ }^{[20]}$. In a large hospital center all short term sick leaves result in a lot of absenteeism and financial losses.

As in the Republic of Croatia work injuries and professional sick leave is compensated with $100 \%$ of the pay, the problem is the nurse's return to her job after sick leave. One has to understand nurses who actually do two jobs. One is at home with family and children and one at her official workplace. They are burdened with shift work, potential danger and accumulated tiredness. Therefore medical workers sometimes try with various diagnoses to make it easier for themselves by prolonging the sick leave. It takes a very experienced occupational medicine specialist to assess objectively the patient's condition and make the right decision. Downsizing is everywhere, not only of non-medical but also of medical personnel. Hospitals manage to go on functioning but it causes complications and burdens the remaining employees ${ }^{[21]}$.

All of those mainly apply to developed countries or those with well-developed health system like the one in the Republic of Croatia. Of course, there are also developing countries with little means, medication, equipment and medical workers ${ }^{[22]}$. In spite of tremendous difficulties that medical staff endures they find great satisfaction in the results of their care and treatment.

It is well known that medical workers will always do their best to give the patient care and pleasure, often not sparing themselves regardless of the condition they work in.

\section{Conclusion}

The purpose of the paper and discussion is to "remind" the management at the head of health system that human resources are its most important part. Medical workers have to be satisfied, financially stimulated and awarded, provided with health care and control. In the Republic of Croatia large companies and institutions with over 250 employees are to have an occupational safety and health unit. It cooperates with Occupational medicine which checks the employees that do the jobs requiring special working conditions. The increased MN findings showed that something went wrong. Intervention measures are required and Occupational medicine has at its disposal a number of measures to improve unfavorable ecological conditions. That includes introducing and educating new nurses to diminish the days of exposure, to introduce 
the so-called worker's rotation, to control digestors and install new ones if necessary, to supply more protective clothing, overcoats, gloves, aprons, shoes and masks.

Another purpose of this paper is to solve permanently the problem of financing such tests. It is known that they are needed and in fact obligatory but in practice the bills do not get paid which makes it difficult for new employees who work with cytostatics to be examined.

Also, it is important to mention, the paper does not refer only to Croatia but globally because recession is unfortunately global and it hit wealthier countries than Croatia too. All medical workers around the world doing the jobs that require special working conditions must be enabled to have such tests that the profession and science proved to be necessary.

At the end let us try to confirm the title. The micronuclei test has been proved to be a very important one in monitoring health of exposed medical personnel in our country and elsewhere ${ }^{[23]}$. Although the nurses' routine laboratory findings were normal, the changes due to exposure to cytostatics were detected only by the mentioned test. It usually takes 6 months for the cells to recover, but already after 3 months the number of micronuclei in the exposed nurses was partially diminished after they had been removed from their workplace. Therefore it is necessary that the MN test for the personnel exposed to cytostatics should become routine and financial means for that purpose must be found.

\section{Acknowledgements}

The author gratefully acknowledges the help of the laboratory and scientific staff of the Mutagenesis unit at the Institute for Medical Research and Occupational Health (Zagreb, Croatia), who performed all microscopic analyses.

\section{Competing interests}

There are no competing interests. The paper is written and then translated into English language by the author's personal funds.

\section{References}

[1] Lalic, H. Cytogenetic monitoring of medical staff professionally exposed to Gamma and X radiation. Neoplasma. 2005; 52(4): 307-13. PMid:16059647

[2] Maffei, F., Angelini, S., Forti, GC., Violante, FS., Lodi, V., Mattioli, S., Hrelia, P. Spectrum of chromosomal aberrations in peripheral blood lymphocytes of hospizal workers occupationally exposed to low doses of ionizing radiation. Mutat Res. 2004; 547(1-2): 91-9. PMid:15013703 http://dx.doi.org/10.1016/j.mrfmmm.2003.12.003

[3] Zakeri, F. and Hirobe, T. A Cytogenetic approach to the effects of low levels of ionizing radiations on occupationally exposed individuals. Eur J Radiol. 2010; 73(1): 191-5. PMid:19054641 http://dx.doi.org/10.1016/j.ejrad.2008.10.015

[4] Wiesner, G., Schiewe-Langgartner, F., Lindner, R., Gruber, M. Increased formation of sister chromatid exchanges, but not of micronuclei, in anaesthetists exposed to low doses of sefoflurane. Anaesthesia. 2008; 63(8): 861-4. PMid:18540930 http://dx.doi.org/10.1111/j.1365-2044.2008.05498.x

[5] Yang, DP., Xu, SJ., Wang, JX. Study on chromosome damage among nurses occupationally exposed to antineoplastic drugs in an oncology department. Biomed Environ Sci. 2002; 15(3): 268-70. PMid:12500668

[6] Fenech, M. The cytokinesis-block micronucleus technique: a detailed description of the method and its application to genotoxicity studies in human populations. Mutat Res. 1993; 288: 35-44. http://dx.doi.org/10.1016/0027-5107(93)90049-L

[7] Norppa, H., Luomahaara, H., Roth, S., Sorsa, M., Renzi, L., Lindholm, C. Micronucleus assay in lymphocytes as a tool to biomonitor human exposure to aneuploidogens and clastogens. Environ Health Persp. 1993; 101(Suppl 3): 139-43. PMid:8143606

[8] Albertini, RJ., Nicklas, JA., O’Neil, JP. Future research directions for evaluating human genetic and cancer risk from environmental exposures. Environ Health Persp. 1996; 104 (Suppl 3): 503-10. PMid:8781373

[9] Kopjar, N., Kašuba, V., Milić, M., Rozgaj, R., Želježić, D., Gajski, G., Mladinić, M., Garaj-Vrhovac, V. Micronucleus assay in Croatian general population. Arh Hig Rad Toksikol. 2010; 61: 219-234. http://dx.doi.org./10.2478/10004-1254-61-2010-2027.

[10] Lalić, H. A case report of occupational middle ear tuberculosis in a nurse. Arh Hig Rad Toksikol. 2010; 61(3): 333-7. PMid:20860974 http://dx.doi.org/10.2478/10004-1254-61-2010-2034 
[11] Murgia, E., Ballardin, M., Bonassi, M., Rossi, AM., Barale, R. Validation of micronuclei frequency in peripheral blood lymphocytes as early cancer risk biomarker in a nested case-control study. Mutat Res. 2008; 639: 27-34. PMid:18155071 http://dx.doi.org/10.1016/j.mrfmmm.2007.10.010

[12] Lalić, H. Occupational medicine in taking over work injuries from family practice - a one year follow -up. Coll Antropol. 2010; 33(3): 939-43.

[13] Lalić, H. International Occupational Medicine:Croatia. Occup Med Lond. 2008; 58(5): 376. PMid:18676428 http://dx.doi.org/10.1093/occmed/kqn060

[14] Lalić, H. et Hromin, M. Presenteeism towards absenteeism: manual work versus sedentary work, private versus governmental - a Croatian review. Coll Antropol. 2012; 36(1): 111-6. PMid:22816206

[15] Blanca Gutierrez, JJ., Del Rosal Gonzalez, A., de Los Angeles Gonzalez Abalos, M., Aceituno Herrera, A., de Rivera, JC., Arjona Gonzalez, A. Effect of the introduction of „demand“ nursing shifts on hours of absenteeism. Gac Sanit. 2012; 26(5): 480-2. PMid:22464024

[16] Nillson, A., Denison, E., Lindberg, P. Life values as predictors of pain, disability and sick leave among Swedish registered nurses: a longitudinal study. BMC Nurs. 2011; 29: 10-17.

[17] Gaudine, A. et Thorne, L. Nurses' ethical conflict with hospitals: a longitudinal study of outcomes. Nurs Ethics. 2012; 22 May (Epub ahead of print). PMid:22619238 http://dx.doi.org/10.1177/0969733011421626

[18] Estorce, TP et Kurcgant, P. Sick leave and nursing personnel management. Rev Esc Enferm. 2011; USP 45(5): $1199-205$.

[19] Tucker, SJ., Weymiller, AJ., Cutshall, SM., Rhudy, LM., Lohse, CM. Stress ratings and health promotion practices among RNs: a case for action. J Nurs Adm. 2012; 42(5): 282-92. PMid:22525292 http://dx.doi.org/10.1097/NNA.0b013e318253585f

[20] Moret, L., Anthoine, E., Paille, C., Tricaud, L., Gerbaud, L., Giraud-Roufast, A., Michel, P., Lombrail, P. Relationship between inpatient satisfaction and nurse absenteeism: an exploratory study using WHO-PATH performance indicators in France. BMC Res Notes. 2012; 31(5): 83. PMid:22293709 http://dx.doi.org/10.1186/1756-0500-5-83

[21] Panknin, HT. Complications caused by personnel downsizing: the hospital survives. Pflege Z. 2005; 58(6): 347-50. PMid:16013283

[22] Khan, MM., R Hotckiss, D., Dmytraczenko, T., Zunaid Ahsan,. Use of Balanced Scorecard in strengthening health systems in developing countries: an analysis based on nationally representative Bangladesh Health Survey. Int J Health Plann Manage. 2012; Aug 9 (Epub ahead of print). http://dx.doi.org./10.1002/hpm.2136.

[23] Mrđanović, J, Jungić, S., Šolajić, S., Bogdanović, V., Jurišić, V. Effects of orally administered antioxidants on micronuclei and sister chromatid exchange frequency in workers professionally exposed to antineoplastic agents. Food Chem Toxicol. 2012; 50(8): 37-44. PMid:22546365 http://dx.doi.org/10.1016/j.fct.2012.04.027 